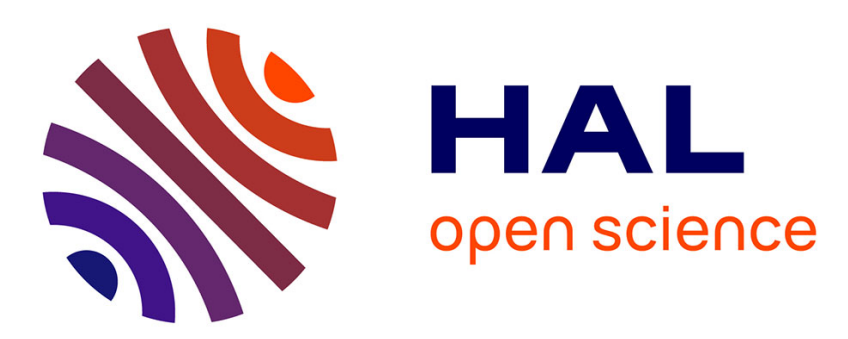

\title{
Characterization of mechanically perturbed young stems: can it be used for wood quality screening?
}

Luis Apiolaza, Butterfield, Shakti Chauhan, John Walker

\section{To cite this version:}

Luis Apiolaza, Butterfield, Shakti Chauhan, John Walker. Characterization of mechanically perturbed young stems: can it be used for wood quality screening?. Annals of Forest Science, 2011, 68 (2), pp.407-414. 10.1007/s13595-011-0028-8 . hal-00930763

\section{HAL Id: hal-00930763 \\ https://hal.science/hal-00930763}

Submitted on 1 Jan 2011

HAL is a multi-disciplinary open access archive for the deposit and dissemination of scientific research documents, whether they are published or not. The documents may come from teaching and research institutions in France or abroad, or from public or private research centers.
L'archive ouverte pluridisciplinaire HAL, est destinée au dépôt et à la diffusion de documents scientifiques de niveau recherche, publiés ou non, émanant des établissements d'enseignement et de recherche français ou étrangers, des laboratoires publics ou privés. 


\title{
Characterization of mechanically perturbed young stems: can it be used for wood quality screening?
}

\author{
Luis A. Apiolaza • Brian Butterfield • \\ Shakti S. Chauhan • John C. F. Walker
}

Received: 18 February 2010 / Accepted: 26 August 2010 /Published online: 23 February 2011

(C) INRA and Springer Science+Business Media B.V. 2011

\begin{abstract}
- Introduction Genetic testing is the slowest part of a breeding cycle. There is a growing interest in early wood quality screening methodologies. We hypothesized that subjecting 8-month-old radiata pine trees to mechanical perturbance induces reaction wood that permits isolating their likely corewood features.

- Methods Four clones were grown straight, tied at $45^{\circ}$ from the vertical, or rocked on a purpose-built frame. Trees were assessed for growth, basic density, compression wood, number of resin canals, and three acoustic stiffness (MoE) measures with an ultrasonic timer.

- Results There were no significant differences between stem postures for growth. Both rocked and straight trees developed similar levels of compression wood (between $13 \%$ and $17 \%$ ). Rocked trees had a significantly larger number of resin canals than straight trees. Rocked trees produced the lowest $\mathrm{MoE}$ for all acoustic assessments. Clonal rankings for MoE were consistent between standing tree and green stemwood MoE. There were small ranking differences for dry stemwood MoE. Clone F, which expresses low MoE as an adult tree, had consistently the lowest $\mathrm{MoE}$ assessments but also the highest basic density.
\end{abstract}

Handling Editor: Barry Gardiner

L. A. Apiolaza $(\bowtie) \cdot S$. S. Chauhan · J. C. F. Walker

School of Forestry, University of Canterbury,

Private Bag 4800,

Christchurch, New Zealand

e-mail: Luis.Apiolaza@canterbury.ac.nz

B. Butterfield

School of Biological Sciences, University of Canterbury,

Private Bag 4800,

Christchurch, New Zealand
- Conclusion The observed differences in wood properties between clones make feasible their use for screening purposes at an early age.

Keywords Clones · Compression wood - Early selection . Wood stiffness $\cdot$ Acoustic assessments

\section{Introduction}

For any given tree species, there is an immense within- and between-tree variability in wood quality. This phenotypic variability is an expression of the genetic background of the trees (their genotype), and the site and silvicultural conditions under which they have developed (their environment). Those studying wood quality face the difficulty of disentangling this variability. This requires a large number of individuals, while working with physically large and long-lived organisms. Many published studies have too few trees to be useful to characterize and exploit population variability. Consequently, there is a pressing need to screen for wood quality using large numbers of individuals when the trees are small and as young as possible.

The corewood of radiata pine (Pinus radiata D. Don), defined arbitrarily as the first 10 growth rings, is deemed to have poor physical and chemical properties. Corewood is often called juvenile wood, although there are distinctions between the two terms (see Burdon et al. 2004 for a discussion). Corewood is laid down where tree stems need to flex, and the anatomical features and properties reflect this function. More accurately, corewood is characterized by a steady change in chemical and physical properties with increasing ring number, which is often considered favorable for wood processing purposes. Thus, the corewood in the 
first growth ring has the shortest tracheids with the thinnest cell walls, little latewood formation, and the highest S2 microfibril angles - the latter is comparable to that found in compression wood (Nakada 2007).

In addition, young radiata pine is notorious for its undesirable stem form and consequently is prone to develop compression wood, particularly near the ground line. For example, according to Burdon (1975), very mild to severe compression wood in 12-year-old trees accounted for 34\% to $44 \%$ of the stem volume, while Timell $(1986, \mathrm{p} 4)$ makes reference to values of $15 \%$. Tree breeders with their early focus on vigorous growth and stem straightness have produced, fortuitously, improved genotypes that are more prone to form mild compression wood than less vigorous trees (Shelbourne et al. 1969).

The five detailed categories/grades of compression wood adopted by Burdon (1975) and later by Donaldson et al. (2003) require consideration of two separate matters: the "quality" and the "quantity" of compression wood. Quality presents a continuous spectrum, such that lumber (timber) with mild compression wood poses few problems, whereas severe compression wood (particularly if unevenly distributed within the lumber) is an obvious defect that results in excessive longitudinal shrinkage, distortion, and other problems during drying and machining. Unfortunately, this assessment of compression wood is too complex to incorporate in any rapid, mass screening of breeding populations.

Leading shoots, irrespective of the age and size of the tree, are flexed by wind. Some of the wood in flexing stems has been described as "flexure wood" by Telewski (1989). Flexure wood has been reported to have some of the characteristics of compression wood while showing significant differences. A high MFA in short cells is therefore not unexpected in flexure wood, but other compression wood characteristics such as intercellular spaces, rounded cells, and loss of the S3 wall layer are not usual features. Whereas compression wood on the underside of a leaning stem is subject to continuous and sustained compression load, when the stem is swaying in the wind, the wood is alternately stretched and compressed.

Initial tree stocking and tree position within a stand have a direct influence on wind exposure. Grabianowski et al. (2004) and Lasserre et al. (2005) showed that wood stiffness was reduced in radiata pine stands with low stocking and exposed sites. A similar situation has been reported for several Eucalyptus species (Warren et al. 2009). Trees in the margins of stands are also more exposed to stem flexing and show lower wood stiffness (Bascuñán 2004; Bascuñán et al. 2006, Bruchert and Gardiner 2006).

Apiolaza (2009) suggested targeting very early wood quality thresholds in corewood with the aim of breeding trees for stiffness and stability. There is a question on how early can we reliably observe wood quality differences between genotypes, particularly when normal wood is commingled with both compression and flexure wood.

In order to better understand genetic and environmental effects in young stems, we established a series of experiments with plants of radiata pine isolating the different types of wood. We hypothesized that the wood quality of 8month-old trees provides information on their likely corewood features, compression wood formation, and the impact of wind. This study characterized only four genotypes at the extremes of the wood stiffness distribution, assuming that if we cannot find distinctions between the extremes, there is no need for investing in a broaderalthough less differentiated-genetic base. The difference between stems subject to sustained loads and those flexed were examined both by leaning and mimicking wind by rocking trees in a seesaw frame. It is important to highlight that this study was not concerned with reaction wood per se, but on isolating its effects to improve early screening of wood quality, particularly by reducing variation that leads to less random noise in vertical stems.

\section{Materials and methods}

Nursery seedlings of radiata pine plants of four clones were potted in rigid plastic tubes and grown either vertically (straight), tied to stakes at $45^{\circ}$ to the vertical (leaning), or rocked on a purpose built frame (rocked). Two months after potting, the trees in the frame were rocked intermittently, 24 cycles/minute over an arc of $44^{\circ}\left( \pm 22^{\circ}\right.$ to the vertical) for $15 \mathrm{~min}$ in every hour for a further 6 months. The standardized predicted genetic values for stiffness of the four clones (coded as A, F, K, and $\mathrm{W}$ ) covered the range of the variable, from the bottom decile (clone $\mathrm{F}$ ) to the top decile (clone $\mathrm{K}$ ). The rocked plants were clamped just above the ground line to prevent stem rotation below that point and to avoid roots being stressed. The initial design envisaged 12 ramets (genetically identical individuals) per clone for each stem posture, a number that balanced sample size calculations (van Belle 2003), previous experience with clonal trials and space available for the experiment. However, only clones $\mathrm{A}$ and $\mathrm{K}$ were leaned due to plant availability. There was additional imbalance due to plant mortality and the use of more ramets for clones $\mathrm{F}$ and $\mathrm{W}$. The final number of ramets per clone was: 36 A (Leaned: 12, Rocked: 12, Straight: 12), 19 F (Rocked: 8, Straight: 11), $37 \mathrm{~K}$ (Leaned: 11, Rocked: 13, Straight: 13), and $31 \mathrm{~W}$ (Rocked: 12, Straight: 19).

At the end of the experiment, the plants were assessed for stem diameter at the ground line (DIAM, the mean of two perpendicular assessments in $\mathrm{mm}$ ), height (HT, $\mathrm{cm}$ ), and standing tree acoustic velocity ( $\mathrm{SV}, \mathrm{km} \mathrm{s}^{-1}$ ) using a Fakkop ultrasonic timer (frequency $90 \mathrm{kHz}$ ). The average 
distance between the probes (tip to tip) was $150 \mathrm{~mm}$, and a time correction factor of $14 \mu \mathrm{s}$ was used to compensate for the pulse propagation within the probes. Probes were inserted into wood at an angle of $45^{\circ}$ with the stem axis. The plants were then destructively sampled with a short length being taken from just above ground level. In rocked stems, the sample was taken from just above the clamp. These debarked butt sections, 120 to $150 \mathrm{~mm}$ long, were reassessed for longitudinal green $\left(\mathrm{GV}, \mathrm{km} \mathrm{s}^{-1}\right)$ and dry (DV, $\mathrm{km} \mathrm{s}^{-1}$ ) velocity assessments using an ultrasonic timer with probes inserted on the transverse faces, and for basic density (BDEN, $\mathrm{kg} \mathrm{m}^{-3}$ ). Dried samples retained about $4 \%$ moisture content as the drying was carried out at $35^{\circ} \mathrm{C}$ to avoid any thermal degradation of cell wall constituents as the specimens were destined for further chemical analysis. In all acoustic measurements, it was ensured that the probes penetrated to a uniform depth.

Dynamic MoE (in GPa) was estimated for each of the acoustic assessments, producing standing tree $\mathrm{MoE}(\mathrm{SMoE}$, green density $\times \mathrm{SV}^{2}$ ), and both green longitudinal $\mathrm{MoE}$ $\left(\mathrm{GMoE}\right.$, green density $\left.\times \mathrm{GV}^{2}\right)$ and dry longitudinal $\mathrm{MoE}$ $\left(\mathrm{DMoE}\right.$, basic density $\left.\times 1.14 \times \mathrm{DV}^{2}\right)$ of the stems segments. The 1.14 adjustment factor in the calculation of $\mathrm{DMoE}$ allows for the shrinkage from the green to dry state as the average volumetric shrinkage measured in a subset of samples was $14 \%$. Green wood density was assumed to be $1,100 \mathrm{~kg} \mathrm{~m}^{-3}$ (Chauhan and Walker 2006).

Disks were also cut from a subsample of 37 stems of clones $\mathrm{A}$ and $\mathrm{K}$, covering all postures. One cross section per stem was cut using a microtome, stained with Safranin and examined by microscope. Percent compression wood (\% of total section area) in whole stem transverse sections was determined by differential staining under carefully controlled conditions, followed by disk scanning at 48 bit color and 1,200 dpi, and image thresholding to isolate compression wood. All image processing was conducted in Adobe Photoshop CS4 (Adobe Systems Inc, version 11). For each section, the resin canals (RC) were counted in two randomly placed orthogonal traverses. The counted area was measured with a micrometer slide and graduated eyepiece to measure accurately the diameter of the field of view while using a $\times 10$ eyepiece with $\times 10$ objective. This permitted calculating the viewable cross section (in $\mathrm{mm}^{2}$ ) and expressing resin canals per $\mathrm{mm}^{2}$.

Data were analyzed as a two-factor completely randomized design. Thus, the response variable for tree $i j k\left(y_{\mathrm{ijk}}\right)$ was expressed as a function of the overall mean $(\mu)$, clone $i\left(C_{\mathrm{i}}\right)$, stem posture $j\left(S_{\mathrm{j}}\right)$, their interaction $\left(C S_{\mathrm{ij}}\right)$, and a random residual $\left(e_{\mathrm{ijk}}\right)$ :

$y_{\mathrm{ijk}}=\mu+C_{\mathrm{i}}+S_{\mathrm{j}}+C S_{\mathrm{ij}}+e_{\mathrm{ijk}}$

Multiple post hoc comparisons were performed using a Tukey test, and significance tests were conducted at the 95\% confidence level $(P<0.05)$. All the analyses were performed with the statistical software R (R Development Core Team 2009).

\section{Results}

Descriptive statistics for the assessed variables are presented in Table 1, with values calculated across tree postures and clones. The resin canal count (RC) presented the largest coefficient of variation of all variables (26.9\%). All proxies for wood stiffness (SMoE, GMoE, and DMoE) also presented large coefficients of variation (between $14.4 \%$ and $20.2 \%$ ). A similar situation was observed for growth traits with variability between $13.8 \%$ and $16.8 \%$. In contrast, BDEN had a low variability, with a coefficient of variation of $7.2 \%$.

Only six out of the 15 correlations were significant (italicized in Table 1). The only strong associations were between height and diameter $(r=0.66)$, and dry and green MoE $(r=0.55)$; the other significant correlations were mod-

Table 1 Descriptive statistics for tree height (HT), basal diameter (DIAM), wood basic density (BDEN), and dynamic modulus of elasticity for standing tree (SMoE), green stemwood (GMoE), dry stemwood (DMoE), and number of resin canals (RC)

\begin{tabular}{|c|c|c|c|c|c|c|c|c|c|}
\hline Trait & Number & Mean & SDev & CVar & HT & DIAM & BDEN & $\mathrm{SMoE}$ & GMoE \\
\hline $\mathrm{HT}(\mathrm{cm})$ & 123 & 83.33 & 14.01 & 16.82 & & & & & \\
\hline DIAM (mm) & 123 & 12.92 & 1.78 & 13.74 & 0.66 & & & & \\
\hline BDEN $\left(\mathrm{kg} \mathrm{m}^{-3}\right)$ & 98 & 384.94 & 27.75 & 7.21 & -0.07 & -0.11 & & & \\
\hline SMoE (GPa) & 123 & 2.16 & 0.44 & 20.15 & 0.09 & -0.02 & -0.09 & & \\
\hline GMoE (GPa) & 98 & 3.54 & 0.65 & 18.51 & 0.21 & -0.13 & 0.20 & 0.34 & \\
\hline $\mathrm{DMoE}(\mathrm{GPa})$ & 98 & 4.01 & 0.58 & 14.36 & -0.01 & 0.04 & 0.12 & 0.39 & 0.55 \\
\hline $\mathrm{RC}$ & 37 & 30.72 & 8.26 & 26.87 & & & & & \\
\hline
\end{tabular}

The statistics include number of samples $(\mathrm{N})$, arithmetic mean, standard deviation (SDev), coefficient of variation (CVar, \%), and Pearson correlations between variables. Statistically significant correlations $(P<0.05)$ are italicized 
erate with magnitudes between 0.20 and 0.39 . Tree diameter showed no significant association with wood traits, while height showed a positive moderate association with green $\operatorname{MoE}(r=0.21)$.

The associations between different assessments of wood stiffness were consistent, with a positive association for standing tree SMoE with green stemwood $\mathrm{GMoE}(r=0.34)$ and with dry stemwood DMoE $(r=0.39)$. In addition, there was a positive association between green and dry stemwood $\operatorname{MoE}(r=0.55)$. No correlations were estimated between RC and other variables, because of the small sample size (37) and representation of only two clones.

The results for the analyses of variance are presented in Table 2. Only main effects (stem posture, clone, or both) were significant, with no significant interaction $(P>0.05)$ between them for any of the variables.

There were no significant differences for HT and DIAM (over bark at the ground line) due to stem posture; however, clone $\mathrm{W}$ was significantly taller $(89.4 \mathrm{~cm})$ than clone A $(79.4 \mathrm{~cm})$. Average DIAM for the clones varied between $12.7 \mathrm{~mm}$ (clone W) and $13.2 \mathrm{~mm}$ (clone A) but with no significant differences.

BDEN was significantly different for all postures, ranging from $367.6 \mathrm{~kg} \mathrm{~m}^{-3}$ for straight trees to $418.0 \mathrm{~kg} \mathrm{~m}^{-3}$ for leaned trees. There were significant differences between clones $\mathrm{F}$ and $\mathrm{W}$ with clones $\mathrm{K}$ and $\mathrm{A}$. In general, taller clones were also denser.

Across all assessments, the lowest MoE was for rocked trees. However, significances for stem posture were not consistent across assessments, with rocked trees being different for SMoE and DMoE, but no significant differences for $\mathrm{GMoE}$.

Clonal rankings were consistent between $\mathrm{SMoE}$ and GMoE, reducing in order $\mathrm{W}, \mathrm{K}, \mathrm{A}$, and $\mathrm{F}$. This situation changed for DMoE, where clone $\mathrm{K}$ had the highest $\mathrm{MoE}$ followed by A, W, and F. Nevertheless, the differences between clones $\mathrm{K}$ and $\mathrm{A}$ were not significantly different for any of the acoustic assessments. Clone $\mathrm{F}$ had consistently the lowest $\mathrm{MoE}$ assessments $(1.8,3.0$, and $3.4 \mathrm{GPa}$ for $\mathrm{SMoE}, \mathrm{GMoE}$, and $\mathrm{DMoE}$, respectively) but also the highest basic density $\left(418.2 \mathrm{~kg} \mathrm{~m}^{-3}\right)$.

Rocked trees showed a significantly larger number of $\mathrm{RC}$ than leaned and straight trees. The resin canal count difference between clones A and K (4.4) was not large enough to qualify as significant $(P=0.08)$.

Despite the lack of significant interaction between stem posture and clone $(P=0.11)$, the difference of $\mathrm{SMoE}$ between straight and rocked conditions was not the same for all clones. Clones A, K, and $\mathrm{W}$ expressed a significant change of $\mathrm{SMoE}$ when moving from straight to rocked conditions; in contrast, the change was almost negligible for clone F (Fig. 1). The SMoE difference between clones A and $\mathrm{K}$ was magnified under leaning.

As might be expected, the plants grown at an angle of $45^{\circ}$ developed the largest percentage of compression wood (33\% of the wood cross-sectional area). The cut stems showed typical eccentric growth with wider growth rings on the lower side containing thicker-walled darker cells (Fig. 2b). Anatomically, these tracheids were rounded in outline with intercellular spaces, and possessed helical checks in their S2 wall layers. The S3 wall layer was generally absent.

In comparison, the stems of both the vertically grown plants and those grown in the rocker (Fig. 2a) showed little compression wood $-17 \%$ of the total section area in the vertical plants and $13 \%$ in the rocked ones. Where present, any compression wood in the stems of the rocked plants was not correlated to the axis of rocking (Fig. 2a), but occurred in a seemingly random pattern (location, area, and intensity) that was governed more by the position of the lateral branches above the cut stemwood zone than to the stresses induced by the rocking. The tracheids in the wood on either side of the plane of rocking showed normal features except for the occasional loss of the S3 wall layer and occasional S2 wall checking in some tracheids.

Table 2 Posture and clone means (and their standard errors) for all traits

\begin{tabular}{llllllll}
\hline & HT $(\mathrm{cm})$ & DIAM $(\mathrm{mm})$ & BDEN $\left(\mathrm{kg} \mathrm{m}^{-3}\right)$ & SMoE $(\mathrm{GPa})$ & GMoE $(\mathrm{GPa})$ & $\mathrm{DMoE}(\mathrm{GPa})$ & $\mathrm{RC}$ \\
\hline Posture & & & & & & & \\
Leaning & $77.8(2.9) \mathrm{A}$ & $13.1(0.4) \mathrm{A}$ & $418.0(3.7) \mathrm{A}$ & $2.16(0.08) \mathrm{A}$ & $3.61(0.13) \mathrm{A}$ & $4.27(0.11) \mathrm{A}$ & $28.0(2.1) \mathrm{A}$ \\
Rocked & $83.5(1.9) \mathrm{A}$ & $12.7(0.3) \mathrm{A}$ & $380.8(2.8) \mathrm{B}$ & $1.92(0.05) \mathrm{B}$ & $3.45(0.10) \mathrm{A}$ & $3.83(0.08) \mathrm{B}$ & $34.9(2.0) \mathrm{B}$ \\
Straight & $85.5(1.8) \mathrm{A}$ & $13.0(0.2) \mathrm{A}$ & $367.6(3.0) \mathrm{C}$ & $2.35(0.05) \mathrm{A}$ & $3.59(0.11) \mathrm{A}$ & $4.06(0.08) \mathrm{AB}$ & $28.4(2.4) \mathrm{A}$ \\
Clone & & & & & & & \\
A & $79.4(2.2) \mathrm{A}$ & $13.2(0.3) \mathrm{A}$ & $372.5(2.9) \mathrm{A}$ & $2.13(0.06) \mathrm{A}$ & $3.41(0.10) \mathrm{A}$ & $4.00(0.08) \mathrm{AB}$ & $28.5(1.8) \mathrm{A}$ \\
$\mathrm{F}$ & $85.5(3.1) \mathrm{AB}$ & $12.9(0.4) \mathrm{A}$ & $418.2(6.8) \mathrm{B}$ & $1.76(0.08) \mathrm{B}$ & $2.99(0.24) \mathrm{A}$ & $3.44(0.19) \mathrm{C}$ & \\
$\mathrm{K}$ & $80.9(2.2) \mathrm{AB}$ & $12.9(0.3) \mathrm{A}$ & $377.4(2.8) \mathrm{A}$ & $2.24(0.06) \mathrm{A}$ & $3.51(0.10) \mathrm{A}$ & $4.24(0.08) \mathrm{A}$ & $32.9(1.7) \mathrm{A}$ \\
$\mathrm{W}$ & $89.4(2.4) \mathrm{B}$ & $12.7(0.3) \mathrm{A}$ & $412.6(4.2) \mathrm{B}$ & $2.34(0.07) \mathrm{A}$ & $4.05(0.15) \mathrm{B}$ & $3.78(0.12) \mathrm{BC}$ & \\
\hline
\end{tabular}

Multiple comparisons between postures and between clones use the same letter to denote not statistically different means 


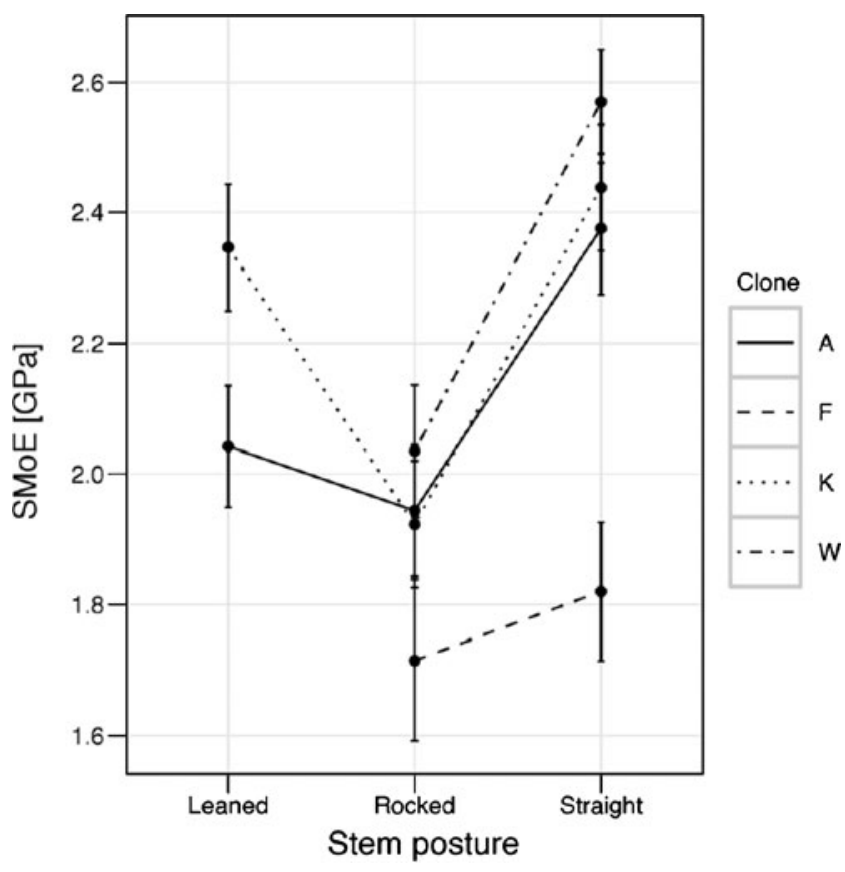

Fig. 1 Changes of standing tree $\mathrm{MoE}(S M O E)$ for different clones under rocked and straight stem postures. Clone F (very low wood stiffness) displays almost no change in contrast with the other three clones, while leaning increased the difference between clones $\mathrm{A}$ and $\mathrm{K}$

Intercellular spaces were not apparent, and the cell walls remained of normal thickness.

Resin canals were counted in microscope slides cut from the rocked and free standing plants. There were a significantly larger number of resin canals $\left(34.9\right.$ per $\left.\mathrm{mm}^{2}\right)$ in the rocked trees than in the free standing trees $(28.4$ per $\mathrm{mm}^{2}$ ). In both treatments, the resin canals were generally circular in outline and surrounded by normal epithelial parenchyma cells. As might be expected from small diameter stems, the resin canals had a tendency to develop in tangential bands, though this pattern was accentuated in the rocked plants (Fig. 3).

\section{Discussion}

\subsection{Growth}

The correlation between HT and DIAM (over bark at the ground line) is on the low side compared to values reported for older trees. However, splitting the data by stem posture shows that the correlation is 0.78 and 0.72 for straight and leaning trees, respectively. The correlation is much lower (0.45) for rocking trees. No significant influence of stem rocking on growth parameters was observed. This is in contrast to the reported effect of mechanical flexing on height and diameter growth in 4-year-old Pinus sylvestris (Mickovski and Ennos 2003) and 9-week-old Ulmus americana (Telewski and Pruyn 1998), but similar to results in 2-year-old Picea sitchensis (Stokes et al. 1997).

The poor associations between growth and wood traits (with only HT correlating with GMoE, Table 1) suggest that early screening for wood quality would not necessarily have a negative impact on breeding for early growth. Further breeding implications for preliminary results of this experiment have been discussed by Apiolaza et al. (2008) and Apiolaza (2009).

\subsection{Acoustics}

The associations between $\mathrm{SMoE}$ and performance in stem segments (GMoE and DMoE) indicate that ultrasonic timeof-flight tools could be useful for very early screening of standing stems, although we prefer using the tool on stem segments. These results are consistent with the suggestions by Lindström et al. $(2002,2005)$ concerning the opportunities for using acoustic tools to mass screen trees for stiffness at a very young age. The correlation between $\mathrm{SMoE}$ and acoustics on stem segments was only moderate ( 0.34 and 0.39 ), and the procedure in the field is not very practical-it is difficult to achieve consistent acoustic coupling between the needle probes and the very small
Fig. 2 Stem cross sections for (a) rocked tree showing compression wood in thin arcs at random and (b) leaning tree showing a continuous wedge of compression wood on the underside of the stem. The doubleended arrow shows the direction of rocking

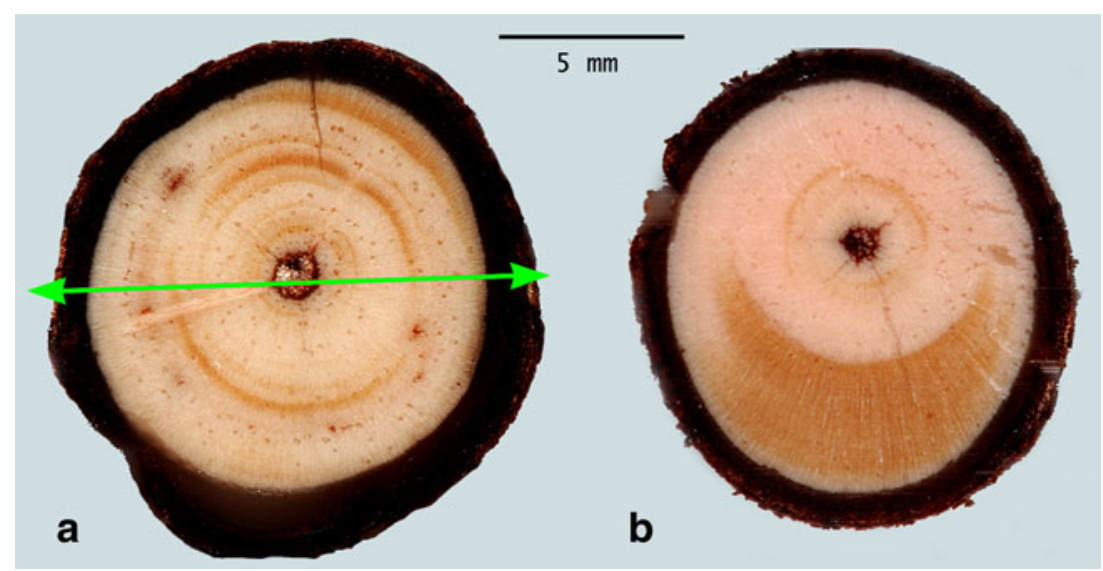


Fig. 3 Resin canals (a) in a random pattern in a straight clone $\mathrm{K}$ tree and $(\mathbf{b})$ in a ring from a rocking clone A tree

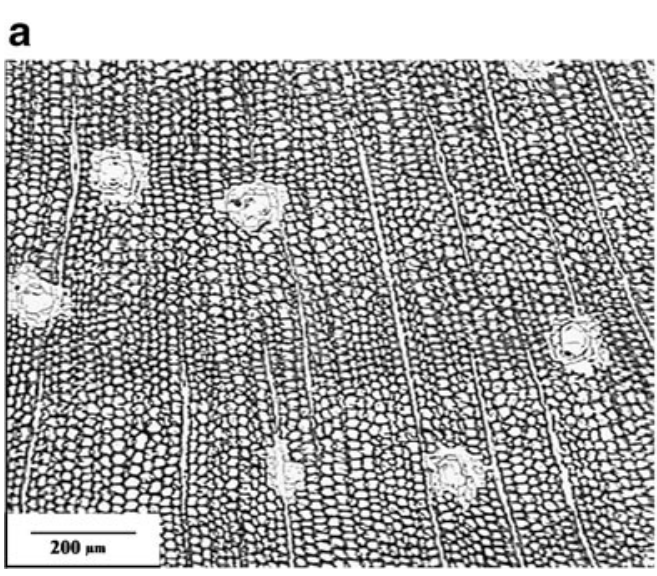

b

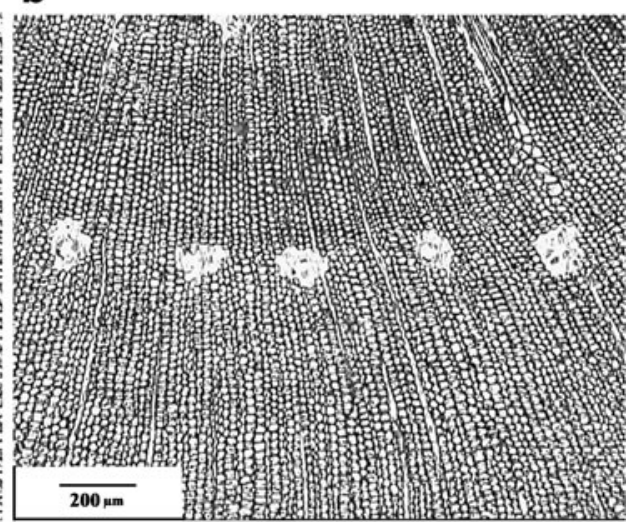

unsupported flexible stems; also the data are sensitive to any small branches in the short path between the probes (100-200 mm apart). This variable has the highest CV of all ultrasonic measurements.

GMoE (3.54 GPa) was significantly higher than SMoE (2.16 GPa). The low SMoE is attributed to the bark attenuating the amplitude of the propagating ultrasonic wave, so delaying the triggering at the set threshold value. In these very thin stems (typically no more than $10 \mathrm{~mm}$ over bark and $8 \mathrm{~mm}$ under bark), the bark contributed noticeably to the area of the cross section. As an indication, the bark volume measured in samples of clones $\mathrm{F}$ and $\mathrm{W}$ was about $30 \%$ of the total volume with bark. GMoE was measured in debarked samples, whereas SMoE was assessed with bark. We have evidence for this effect in the longer recorded transit times for small stems with bark attached compared to the same stems after the bark has been removed. Attenuation of ultrasonic signals in layered structures is well recognized and is caused by the differences in acoustical properties of different layers (Jakevicius et al. 2006). In another study, differences of between $5 \%$ and $30 \%$ were observed in ultrasonic velocity measured in samples with and without bark in green condition (unpublished data). The green density of bark is very similar to the green density of wood, but they are very different in terms of their stiffness.

There was a $21 \%$ reduction of $\mathrm{SMoE}$ from straight $(2.4 \mathrm{GPa})$ to rocked trees $(1.9 \mathrm{GPa})$, consistent with the effect on stand boundaries reported by Bascuñán et al. (2006). However, this difference became nonsignificant for GMoE and DMoE.

Straight and rocked trees were significantly slenderer than leaning trees (data not shown), due to the height difference observed in Table 2. It is unclear that this slenderness difference has any causal relationship with the stiffness difference.

The clonal rankings (i.e., ordering from best to worst) for $\mathrm{MoE}$ at 8-month-old in the glasshouse compare well with that obtained for the SMoE for the same clones at 7 years old in clonal trials (Charles Sorensson, personal communication). The ranking for standardized predicted genetic values (i.e., unitless) for stiffness at age 7 was $\mathrm{K}, \mathrm{W}, \mathrm{A}$, and $\mathrm{F}$ which is very similar to the results obtained from DMoE (Table 2). All methods clearly identified clone $\mathrm{F}$ as the worst performer-a clone that has a significantly lower SMoE (the bottom decile) in adult trees (Sorensson, personal communication). Therefore, it is possible to screen out the worst performers, which show practically significant differences in corewood quality later in life, as early as 8 months of age. Clone F has since been eliminated from operational production as an unprofitable clone for structural purposes.

Changes of acoustic velocity for straight and rocked stems of different clones are given in Fig. 1. It is evident that the flexing stems of clones $\mathrm{A}, \mathrm{K}$, and $\mathrm{W}$ had significantly lower acoustic velocity than the corresponding straight stems, whereas this difference was not significant for clone F. The changes in wood stiffness for rocking stems of $\mathrm{A}, \mathrm{K}$, and $\mathrm{W}$ could be a natural response to optimize the flexibility of the stems in order to prevent structural failure during flexing. This optimization would also depend on stem morphological traits, like height and diameter of the stem. Since there was no significant difference in stem height or collar diameter in straight and rocked stems, we hypothesize that the stems are tending to react to environmental pressures by optimizing mechanical performance through wood stiffness. No significant difference in acoustic velocity was observed in rocked stems of all the clones which suggests that the wood stiffness in all stems tended to achieve the optimal level in order to sustain the dynamic loading during rocking, and since the intrinsic elastic modulus of clone $\mathrm{F}$ was already low enough to sustain dynamic flexure, no changes were observed in acoustic velocity in straight and rocked stems of this clone. Rocking trees provides interesting insights from a research viewpoint; however, it is too complex and expensive to implement at large scale as an operational screening method. 


\subsection{Compression wood}

Although not part of this study, it is suggested that trees be leaned to generate "pure" normal/opposite wood on the upper side and "pure" compression wood on the underside that can be analyzed separately for screening purposes (as pointed out by Nakada 2007). Using a common leaning angle for all trees reduces random occurrence of compression wood in straight stems and tends to increase the observed difference between clones (see Fig. 1). Then, two independent sets of wood quality traits can be gathered, for compression wood and opposite wood (Apiolaza et al. 2011).

Any review of compression must begin by noting (1) that compression wood occurs in vertical stems, (2) that rocked (flexed) wood is not the same as compression wood, and (3) that core/juvenile wood has its poor wood quality characteristics because thin stems flex and consequences are unavoidable. Furthermore, all these are tissue types that are "normal" wood-however, there is a gradation of their expression.

While it is common to use the term "normal wood" as the opposite of compression wood, there is nothing abnormal about the latter. Compression wood also occurs in vertical stems in areas that are subjected to asymmetric loading, with straight trees displaying between $13 \%$ and $17 \%$ of compression wood in the reported experiment. This can be caused by a canopy of irregular shape or it occurs in a tree that is subjected to a unidirectional wind loading, or due to eccentric loading from branches. Although the occurrence of compression wood in inclined stems and branches is well understood and documented, its occurrence in vertical stems is less so, with only a few reports considering young trees (e.g., Lachenbruch et al. 2010). Since the main stem of the tree is of prime concern in production forestry, greater understanding of the occurrence and role of compression wood in vertical or near vertical stems is highly desirable. Radiata pine sawlogs cut from essentially vertical trunks can produce significant amounts of compression wood, ranging from "mild" to "severe." Obviously, leaning, malformed, or heavily limbed trees that are likely to develop severe compression wood are easily identified and can be eliminated at plantation thinning. Trees with milder compression wood in their vertical trunks are more likely to find their way into the mill and result in the unintentional manufacture of possibly unstable lumber.

There are published examples of leaning trees with the purpose of understanding the biomechanics of wood formation and relating results to population variation. For example, Sierra de Grado et al. (2008) studied provenance differences aiming at improving stem form, while Yamashita et al. (2007) studied compression wood development, achieving a maximum degree of reaction wood formation at an angle greater than $20-30^{\circ}$ from the vertical. In contrast, we are suggesting leaning trees specifically for screening purposes.

Differences between compression wood and the wood of rocked trees are to be expected as cell differentiation and maturation occur over several days, whereas the presentation time of a flexing stem is only a matter of seconds. Larson $(1968,1969)$ suggested that a stress stimulus, such as wind or rocking, might induce piezoelectric effects in differentiating wood cells, most likely in the crystalline cellulose. These effects could govern the distribution of auxin in the stem, causing it to move basipetally.

\section{Conclusions}

This study showed that both rocked and straight trees developed similar levels of compression wood (between $13 \%$ and $17 \%$ ). However, rocked trees presented a significantly larger number of resin canals (34.9) than straight trees (28.4). A more comprehensive anatomical description will be required to understand fully the effects of flexing on stems.

Rocked trees produced the lowest $\mathrm{MoE}$; however, the differences between the other two stem postures were not consistent across acoustic assessments. The 20\% stiffness difference between rocked and straight trees detected using SMoE reduced for GMoE (2\%) and DMoE (7\%) becoming nonsignificant. Given the large $\mathrm{CV}$ for $\mathrm{SMoE}$, it is recommended to rely only on acoustics on stem segments (DMoE).

The differences between clones for basic density and wood stiffness were large enough to be useful for screening purposes, particularly when using leaning trees to reduce unwanted variation (noise). In addition, clonal rankings in the glasshouse experiment were consistent with those obtained at age 7 years in clonal tests.

The characterization of very early expression of wood properties could be a useful tool for breeding and deployment of superior trees for stiffness and dimensional stability. These procedures, coupled with targeting corewood instead of rotation age improvement, have the potential to reduce fully genetic testing time for short rotation species.

Acknowledgments The authors thank Nigel Pink, Lachland Kirk, and Michael Weavers (University of Canterbury) for the design and construction of the rocking machine. This project was funded with contributions from FRST Compromised Wood (P2080) Programme and the New Zealand Wood Quality Initiative. We also thank the associate editor and anonymous referees for comments that contributed to improve the quality of the paper.

\section{References}

Apiolaza LA (2009) Very early selection for solid wood quality: screening for early winners. Ann For Sci 66:601 
Apiolaza LA, Chauhan SS, Walker JCF (2011) Genetic control of very early compression and opposite wood in Pinus radiata and its implications for selection. Tree Genet \& Genomes. doi:10.1007/ s11295-010-0356-0

Apiolaza LA, Walker JCF, Nair H, Butterfield B (2008) Very early screening of wood quality for radiata pine: pushing the envelope. In: Proceedings of the 51st International Convention of the Society of Wood Science and Technology, Concepcion, Chile. WQ-1

Bascuñán A (2004) The influence of wind on radiata pine tree shape and wood stiffness. Master of Science Thesis. School of Forestry, University of Canterbury, New Zealand, p 199

Bascuñán A, Moore JR, Walker JCF (2006) Variations in the dynamic modulus of elasticity with proximity to the stand edge in radiata pine stands on the Canterbury Plains, New Zealand. NZ J For $51: 4-8$

Bruchert F, Gardiner B (2006) The effect of wind exposure on the tree aerial architecture and biomechanics of Sitka spruce (Picea sitchensis, Pinaceae). Am J Bot 93:1512-1521

Burdon RD (1975) Compression wood in Pinus radiata clones on four different sites. NZ J For Sci 5:152-164

Burdon RD, Kibblewhite RP, Walker JCF, Megraw RA, Evans R, Cown DJ (2004) Juvenile versus mature wood: a new concept, orthogonal to corewood versus outerwood, with special reference to Pinus radiata and $P$. taeda. For Sci 50:399-415

Chauhan S, Walker JCF (2006) Variations in acoustic velocity and density with age, and their interrelationships in radiata pine. For Ecol Manag 229:388-394

Donaldson LA, Grace JC, Downes G (2003) Within tree variation in anatomical properties of compression wood in radiata pine. IAWA J 23:253-271

Grabianowski M, Manley B, Walker JCF (2004) Impact of stocking and exposure on outerwood acoustic properties of Pinus radiata in Eyrewell Forest. NZ J For 49:13-17

Jakevicius L, Butkus J, Vladisauskas A (2006) Measurement of thickness of layer and sound velocity in multilayered structure by the use of angular ultrasonic transducers. Ultragarsas 58:20-24

Lachenbruch B, Droppelmann F, Balocchi C, Peredo M, Perez E (2010) Stem form and compression wood formation in young Pinus radiata trees. Can J For Res 40:26-36

Larson PR (1968) More on evolution. J For 66:450

Larson PR (1969) Wood formation and the concept of wood quality. Yale Univ School For Bulletin 74:54p
Lasserre JP, Mason EG, Watt M (2005) The effects of genotype and spacing on Pinus radiata (D. Don) corewood stiffness in an 11year old experiment. For Ecol Manag 205:375-383

Lindström H, Harris P, Nakada R (2002) Methods for measuring stiffness of young trees. Holz Roh Werkst 60:165-170

Lindström H, Evans RA, Reale M (2005) Implications of selecting tree clones with high modulus of elasticity. NZ J For Sci 35:50-71

Mickovski SB, Ennos AR (2003) The effect of unidirectional stem flexing on shoot and root morphology and architecture in young Pinus sylvestis trees. Can J For Res 33:2202-2209

Nakada R (2007) Within-tree variation of wood characteristics in conifers and the anatomical characteristics specific to very young trees. In: Walker JCF (ed), The compromised wood workshop, Christchurch, New Zealand, 51-67

R Development Core Team (2009) R: A language and environment for statistical computing. R Foundation for Statistical Computing, Vienna, Austria. ISBN 3-900051-07-0, URL http://www.R-project.org.

Shelbourne CJA, Zobel BJ, Stonecypher RW (1969) The inheritance of compression wood and its genetic and phenotypic correlations with six others traits in five-year-old Loblolly pine. Silvae Genet 18:43-47

Sierra de Grado R, Pando V, Martínez Surimendi P, Peñalvo A, Báscones E, Moulia B (2008) Biomechanical differences in the stem straightening process among Pinus pinaster provenances. A new approach for early selection of stem straightness. Tree Physiol 28:835-846

Stokes A, Nicoll BC, Coutts MP, Fitter AH (1997) Responses of young Sitka spruce clones to mechanical perturbation and nutrition: effects on biomass allocation, root development, and resistance to bending. Can J For Res 27:1049-1057

Telewski FW (1989) Structure and function of flexure wood in Abies fraser. Tree Physiol 5:113-121

Telewski FW, Pruyn ML (1998) Thigmomorphogenesis: a dose response to flexing in Ulmus Americana seedlings. Tree Physiol 18:65-68

Timell TE (1986) Compression wood in gymnosperms. Springer, Berlin

van Belle G (2003) Statistical rules of thumb. Wiley. 221 p.

Warren E, Smith RGB, Apiolaza LA, Walker JCF (2009) Effect of stocking on juvenile wood stiffness for three Eucalyptus species. New For 37:241-250

Yamashita S, Yoshida M, Takayama S, Okuyama T (2007) Stemrighting mechanism in gymnosperm trees deduced from limitations in compression wood development. Ann Bot 99:487-493 